International Journal of Engineering \& Technology, 7 (4.3) (2018) 507-513
International Journal of Engineering \& Technology
SPC
Website: www.sciencepubco.com/index.php/IJET
Research paper

\title{
Application of the Sequential Control for Increasing Competitiveness of Agricultural Products
}

\author{
Vladimir Puzik $^{1}$, Ludmila Puzik ${ }^{1}$, Nina Lyubymova ${ }^{1 *}$, Oksana Pankova $^{1}$, Vitalyi Sakhatsky ${ }^{2}$ \\ ${ }^{1}$ P. Vasilenko Kharkov National Technical University of Agriculture \\ ${ }^{2}$ Kharkov National Automobile and Highway University \\ *Corresponding author E-mail: nina.lioubimova@gmail.com
}

\begin{abstract}
The competitiveness of agricultural enterprises on the international market depends directly on the professional and timely implementation of decisions of control. Its function stipulates for a number of actions, work out methods and tools which aimed at conservation the quality of agricultural products in the period of its storage and transportation in accordance with the consumer's requirements.

Construction of control by a recycling pattern is one of the practical ways to increase the effectiveness of control, when an object that is recognized as fit is subject to repeated checks. The major tasks in the construction of a statistical model of measurement control have been analyzed, a typical monitoring system, a sequential control structure, and its characteristics have been submitted. The suggested control significantly reduces the reject rate in the total mass of products.

The obtained result of analytical dependencies is convenient for engineering calculations of other types of numerical control.

An example of the application of sequential control of broccoli cabbage in its storage with helping with antiseptic preparations is given. The influence of various antiseptics on different varieties of broccoli cabbage is considered. Such a study helps the manufacturer find the best opportunities to improve the competitiveness of its products.
\end{abstract}

Keywords: Agriculture; Antiseptic; Broccoli; Competitiveness; Management quality; Practice; Products; Sequential control.

\section{Introduction}

The problem of quality and marketability of production is relevant at all times. It acquires particular significance, especially at present, in the conditions of formation and development of market relations and Ukraine's entry into the international market of agricultural production. To establish, stabilize and increase production, the enterprise should be competitive. The guarantee and confirmation of its competitiveness is the availability of a quality management system at the enterprise. The general requirements for such a system are set out in international standards [1].

These requirements include a scope of quality management measures which an enterprise ought to carry out in all areas of its production activities - from planning, production output to production distribution $[2,3]$. These functions also provide for a scope of measures, the development of methods and tools seeking to preserve the quality of agricultural products in the period of storage and transportation in accordance with the requirements of the consumer. The program should consist of normative and technical documents that ensure the requirements of international standards for storage, transportation and sales of products, technological maintenance of storage facilities and vehicles; methods and means of control as well as serve the conditions of storage, transportation and sale. The competitiveness of agricultural enterprises in the international market directly depends on the professional and timely implementation of this program.

\subsection{Analysis of Recent Research and Publications}

Control of agricultural products at all stages of manufacturing and marketing has a number of features and difficulties. This marketable product is respondent to many factors, which reduce finally its quality and cost during storage, transportation and sale. These are the time limitations of the above operations, the impact of physical, chemical and biological factors.

Therefore, metrological assurance of product quality includes the whole range of activities seeking to improve the level of work quality and products at all stages of the production cycle by determining and fixing the optimal number of controlled parameters, metrological support of measuring the quality of work and products, and the parameters of technological processes.

The program determines the problems concerning the ascertainment the optimal volume and range of measurable quality indicators; method preparation and selection of measurement instrumentation that ensure the adequate accuracy.

When controlling agricultural products, those methods and means were often used which were employed in industry, but only partially represent the specific character of metrological support of quality control [4-6].

The determining part in the described requirements is assigned to the technological process of manufacturing products, so - to all its distinctive types of control (input, operating, output, etc.). This stimulates enterprises, which are concerned about their image and development prospects, to look for new, more advanced forms of their conduct. This article describes one of these forms. 


\subsection{Identification of Research Object and Problem}

Control is an experimental procedure that establishes whether the object of control conforms to the quality declared by the manufacturer, whether the object is suitable or not suitable for its intended use. However, real control does not give a hundred percent guarantee of the fidelity of their outcomes. An object which was recognized as unfit by it can in fact be suitable (control error of first kind) and, conversely, an object which was recognized as valid may prove to be unfit (error of second kind).

Nevertheless, properly organized control significantly reduces the initial share of waste in the total mass of finished products and ultimately increases its competitiveness. It is natural that the control developer tends to build it so (within the range of the available resources) that this decline was as weighty as possible. In search of effective methods of such control, specialists use different structural constructions of its procedure. In this sense components of control procedure, the elements of which are control procedures, are of interest. In production practice, the concept of repetitive control is well known and has been developed recently. It consists in the object under control, that has been identified as suitable, is subjected to successive repeated verifications. The scope of such checks will be called conventionally sequential control. Particularly, the so-called multi-stage control dovetails into the concept of sequential control. An example of it is the chain shown in $[3,4,7]$ : technological control - control of the QC department - state formal acceptance - consumer incoming control. For example, in the case of grain product control: on-the-spot production check - storage control at the elevator - customer control (when buying) - control when (on) transportation - the consumer incoming control.

This chain consists of several independent, time-separated and space-based procedures. However, a combination of checks with sequential control can be organized as an undivided procedure which is conducted at one "workplace" (in the absence of additional technical means) and on one check-out equipment.

Despite widespread industrial implementation of sequential control, its theoretical evidence has not been consummated to an acceptable result for the practice. In particular, the influential parameters of its substantial carrier (the controlling system) have not been established, as well as the methods of their engineering calculation has not been proposed. The materials in this article make it possible to fill in this gap. The proposed solutions are based on the results obtained by the executors on the basis of processed preliminary statistical data.

\section{Major part of the Study}

\subsection{Statistical Model of Sequential Control. the Prima- ry Task of the Analysis}

Theoretical development of complex control structures (including those considered in this paper) is conveniently carried out on basis of a general statistical control model that is close to real production conditions. In this model, the center of gravity of research is transferred from the personally control to the monitoring system (MS) - the materialized carrier of its functions [8]. The MS itself is considered as a certain converter connected with the external environment by one input and two output channels. We shall call them also its materialized inputs and outputs.

The finite flow (set) of controlled objects enters the MS input. From the MS output two flows are put out. Only those that are recognized as fit by MS are sent to one of these flows. And in the other, only objects which are recognized as unfit. Due to the nonideality of the MS, both output flows turn out loaded by the objects of the opposite quality. The scope and extent of clogging each of these flows exhaustively describe it. Such pairs of parameters, called informative [8], can be made up several. One of them (the number of truly fit ones and the number of truly unfit objects in the flow) is suggested to be considered as a pair of MS varia- bles $[8,9]$. Knowing this pair makes it easy to calculate any other informative flow parameters.

In order to assess the effectiveness of any control, it is necessary to be able to calculate the informative parameters of the MS output flows by the informative parameters of its input flow. Such a calculation assumes knowledge of the comprehensive characteristics of the MS itself. The primary task of analyzing a complex MS, including MS of a sequential control, - is to determine these characteristics.

\subsubsection{General Problem Statement}

The structure of a complex MS is known (its constituent elements and their interconnection with each other and with the external environment). The exhaustive characteristics of all its elements are given. It is required to determine the exhaustive characteristics of the MS S itself.

To date, no rigorous solutions to this problem have been obtained for any of the known complex control structures (at least, the authors did not meet them). In this article, the task is solved for sequential control. The exact analytical correlations which connect the characteristics of the MS with the characteristics of its constituent elements are founded. Let us first consider some general principles on which the proposed solutions are based $[3,8]$.

\subsubsection{Typical MS as a Structural Unit of Sequential Control}

The simplest form of measurement control organization (algorithm) is reduced to a typical sequence of operations: measuring the components of the object's parameter under control, comparing the components values which had been measured with their proper upper and lower tolerance limits, generation of control outcomes - "1" or "0".

The value " 1 " (feature of suitability) is ascribed to the object when all the results of component measurements fall within the boundaries, the value "0" (the feature of reject) - in the case if not one of them falls inside the boundaries.

The described control algorithm is implemented by a typical structural diagram, shown in Fig. 1.

The components of the monitored parameter $\bar{X}=\left(X_{1}, X_{2}, \ldots, X_{n}\right)$ of the unit under test (UT) are measured by a measuring device (MD) [3, 4].

The results of the measurements are compared by the compare facility $(\mathbf{C F})$ with the specified tolerances and the tolerances in its memory. The $\mathbf{C F}$ draw a conclusion about the suitability of the object - "1", if all the results are in the appropriate tolerances, and about worthless of the object - "0", if at least one of the results is out of its tolerance.

Following the established terminology, the set of MD and $\mathbf{C F}$, acting as a materialized carrier of measurement control functions, will be called a measuring typical monitoring system (measuring TMS). Because of its non- singularity (the presence of methodological and instrumental errors in measurement and comparison), control errors occur. The scheme in Fig. 1 represents the most common, but particular variant of TMS and it is given only as a possible example. In general, the control which is implemented by the TMS may not be measurable, it can have a simpler or more complex algorithmic structure. The essence of the studies carried out below and the obtained solutions does not change from this.

When analyzing a complex MS, we are not interested in either the internal structure of the TMS, the type of the monitored parameter (scalar, vector), or the algorithm of the TMS functioning.

The recent is considered as some integration, as a structural unit of the MS, which has three material channels of communication with the external environment (one input and two outputs) and represented by two independent indicators. 


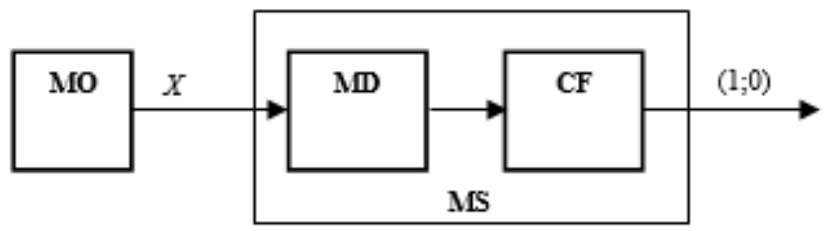

Fig. 1: The structure of measuring control. MO is a monitoring object, MD is a measuring device, CF - a compare facility, MS - a monitoring system, $\vec{X}$ - controlled parameter (vector variable)

One of them $p_{1}^{\prime}$ (a priori conditional producer risk) characterizes the functioning of the system with a view of a knowingly available object and is described by the probability of its rejection. Another $p_{2}$ (ta priori conditional risk of the customer) characterizes with a view of a knowingly faulty object and it is described by the probability of its adoption. Such model is showed in fig. 2 .

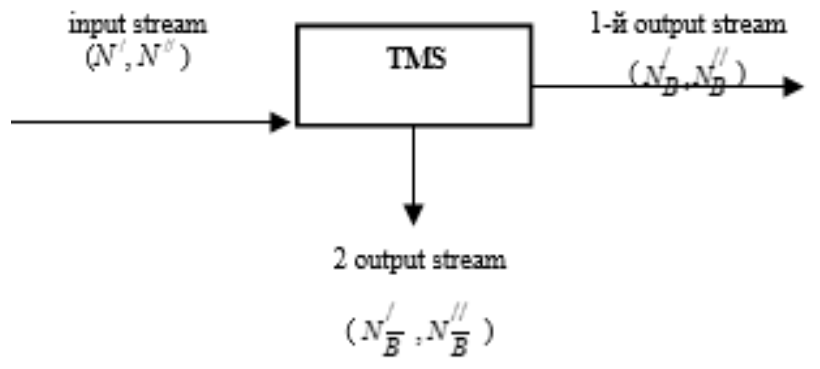

Fig. 2: Typical MS.

TMS - typical monitoring system, $p_{1}^{\prime}, p_{2}^{\prime}$ - indicators of its function$\operatorname{ing},\left(N^{\prime}, N^{\prime /}\right)$ and $\left(N_{B}^{\prime}, N_{B}^{\prime /}\right),\left(N_{\bar{B}}^{\prime}, N_{\bar{B}}^{/ /}\right)$- characteristic parameters of input and output streams of TMS.

Here ( $N^{\prime}$ and $N^{\prime \prime}$ ) are input variables of TMS (the number of really available and really useless objects of its input stream); and - output variables of TCS (the number of truly usable and truly faulty objects, respectively, of its first and second output streams); - indicators of TMS functioning (a priori conditional risks of the manufacturer and the customer) [5].

They exhaustively describe the functioning of a sequential monitoring system.

It is necessary to isolate and analyze each of the streams separately, establish links between them. This will provide a condition of the clogging at the output of the MS system by objects of the opposite quality and assess the effectiveness and quality of the sequential control as a whole.

2.2 Streams characteristics. Input flow. It can be regarded as an indistinguishable composition of two qualitatively different streams, one of which consists only of "fit", and the other - only from "unfit" objects. Denote their quantities, respectively, $N^{\prime}$ and $N^{\prime \prime}$.

$N=N^{\prime}+N^{\prime \prime}$

A relative percentage of the fit objects can be taken as the quality criterion of the input stream. If the volume of the input stream is sufficiently large, it is natural to estimate the relative percentage of fit objects by the probability of the validity of an arbitrary stream object

$p=P\{A\}$

In real control practice, the probability $p$ is often close to unity, and for convenience of comparing such streams in quality it is more convenient to use probability augmenter to unity instead of the probability $p$,

$\bar{p}=1-p=P\{\bar{A}\}$

treating $\bar{p}$ as an assessment of quality losses [10].
The indicator $\bar{p}$, being the probability of "unfitness" of an arbitrarily taken object of the input stream, determines the relative percentage of unfit objects in it. The quantities of fit and unfit objects can be found as products of probabilities for the volume $N$ of the input stream.

$N^{\prime}=p N, N^{\prime \prime}=\bar{p} N=(1-p) N$.

The first output TMS stream. This is a stream of products (objects), in relation to which control takes a positive decision. Recognizing an arbitrary stream object as fit (event B), control is thus the guarantor of its quality [10]. However, the guarantees of control are not 100 percent. "Recognize fit" and "be fit" - unequal events. And only in the case of "ideal" control, they coincide.

Define the characteristics (parameters) of this stream. Denote its volume through $N_{B}$, and the number of its fit and unfit accordingly. Let input also into consideration the probability of entering an arbitrary controlled object into this stream $p_{B}=P\{B\}$

Obviously, the volume $N_{B}$ can be found as the product

$N_{B}=p_{B} N$.

The quality of the stream and its loss are estimated by conditional probabilities

$r=P\{A / B\}$,

$\bar{r}=1-r=P\{\bar{A} / B\}$,

Which determine the relative shares of its fit and unfit objects. The quantities of fit $N_{B}^{\prime}$ and unfit $N_{B}^{\prime \prime}$ stream objects are expressed by the product of the volume $N_{B}$., respectively, by the exponents $r$ and $\bar{r}$

$N_{B}^{\prime}=N_{B} \cdot r, . N_{B}^{\prime \prime}=N_{B} \cdot \bar{r}=N_{B} \cdot(1-r)$.

The second output stream of MS. This stream is rejected, i.e. recognized by the control of unfit production. Ideally, it should consist of all unfit objects of the input stream, and its volume $N_{B}$. should agree with $N^{\prime \prime}$. However, due to the imperfection of control, not all unfit objects on one side and, part of the fit objects on the other hand, get into this stream. Obviously, the volume $N_{B}^{\prime}$ of this stream can be found as the difference between the volumes $N$ and $N_{B}$ or as the product of the volume $N$ by the probability $\bar{p}_{B}$

$N_{\bar{B}}=N-N_{B}=N \cdot\left(1-p_{B}\right)=N \cdot \bar{p}_{B}$.

In the same way as in the previous case, beside of volume $N_{\bar{B}}$, we introduce into consideration the quantities of fit $N_{\bar{B}}^{\prime}$ and unfit stream objects $N \frac{\prime \prime}{B}$ and its quality indicators $\bar{q}$ and quality loss indicators $q$

$\bar{q}=P \cdot\{\bar{A} / \bar{B}\}$,

$q=1-\bar{q}=P \cdot\{A / \bar{B}\}$.

Obviously, the quantities of fit $N_{\bar{B}}^{\prime}$ and unfit $N_{\bar{B}}^{\prime \prime}$ objects expressed through them take the form

$N_{\bar{B}}^{\prime}=N_{\bar{B}} \cdot q, N_{\bar{B}}^{\prime \prime}=N_{\bar{B}} \cdot \bar{q}$.

Several different parameters (indices) are introduced into consideration. They act as characteristics of the MS streams. 
For a compact representation of these parameters, together with their symbolic notations and basic dependencies, are summarized in Table 1.

Table 1: Parameters of monitoring systems streams (TMS)

\begin{tabular}{|c|c|c|c|c|}
\hline № & $\begin{array}{l}\text { Parame- } \\
\text { ters }\end{array}$ & Input stream & $\begin{array}{c}\text { First } \\
\text { Output stream }\end{array}$ & $\begin{array}{l}\text { Second } \\
\text { Output } \\
\text { stream }\end{array}$ \\
\hline 1 & $\begin{array}{l}\text { The prob- } \\
\text { ability of } \\
\text { an object } \\
\text { falling } \\
\text { into a } \\
\text { stream }\end{array}$ & 1 & $p_{B}$ & $\bar{p}_{B}=1-p_{B}$ \\
\hline 2 & $\begin{array}{l}\text { The } \\
\text { stream } \\
\text { value }\end{array}$ & $N$ & $N_{B}=N \cdot p_{B}$ & $N_{\bar{B}}=N \cdot \bar{p}_{B}$ \\
\hline \multirow[b]{2}{*}{3} & \multicolumn{4}{|c|}{ Criterion of quality or of quality loss of a stream } \\
\hline & $\begin{array}{l}\text { Probabil- } \\
\text { ity of the } \\
\text { object } \\
\text { fitness } \\
\text { Probabil- } \\
\text { ity of } \\
\text { object } \\
\text { unfitness }\end{array}$ & $\begin{array}{c}p \\
\bar{p}=1-p\end{array}$ & $\begin{array}{c}r \\
\bar{r}=1-r\end{array}$ & $\begin{array}{c}q \\
\bar{q}=1-q\end{array}$ \\
\hline 4 & $\begin{array}{c}\text { Number } \\
\text { of fit } \\
\text { objects in } \\
\text { the stream }\end{array}$ & $N^{\prime}=N p$ & $N_{B}^{\prime}=N_{B} \cdot r$ & $N_{\bar{B}}^{\prime}=N_{\bar{B}} \cdot q$ \\
\hline 5 & $\begin{array}{c}\text { Number } \\
\text { of unfit } \\
\text { objects in } \\
\text { the stream }\end{array}$ & $N^{\prime \prime}=N \cdot \bar{p}$ & $N_{B}^{\prime \prime}=N_{B} \cdot \bar{r}$ & $N_{\bar{B}}^{\prime \prime}=N_{\bar{B}} \cdot q$ \\
\hline
\end{tabular}

It's given parameters describe the streams of controlled objects in their totality exhaustively. However, only two of them (for each stream) are independent.

Such parameters are informative and can be considered as characteristics of the control system.

\subsection{Sequential Control Structure}

The relevant monitoring system will be called as a sequential MS. It is a series-parallel connection of two, three or more TMSs.

They turn out consistently connected on their inputs and first outputs. This is the main channel for the flow of objects.

Exactly this channel is of the greatest production interest. The second outputs of the TMS are connected in parallel.

Fig. 3 illustrates the structure of the sequential MS. It consists of several typical control systems TMS, $i=1,2, \ldots, n$.

The first output (output stream) of each previous TMS is the input ( input stream) of the subsequent one.

The initial input stream (test lot) enter the input o+-f the first TMS The first output of the last TMS serves as the first output of the MS integrally.

The second outputs (output streams) of all TMSs are combined into one common second connection output.

\subsection{Reference Regulations and Relations}

There some general laws of numerical control are induced in the article [10]. We take these laws as reference statements of research. Let's remind them.

1. Any TMS can be considered as a linear static converter of the input stream of objects under control into two output streams.

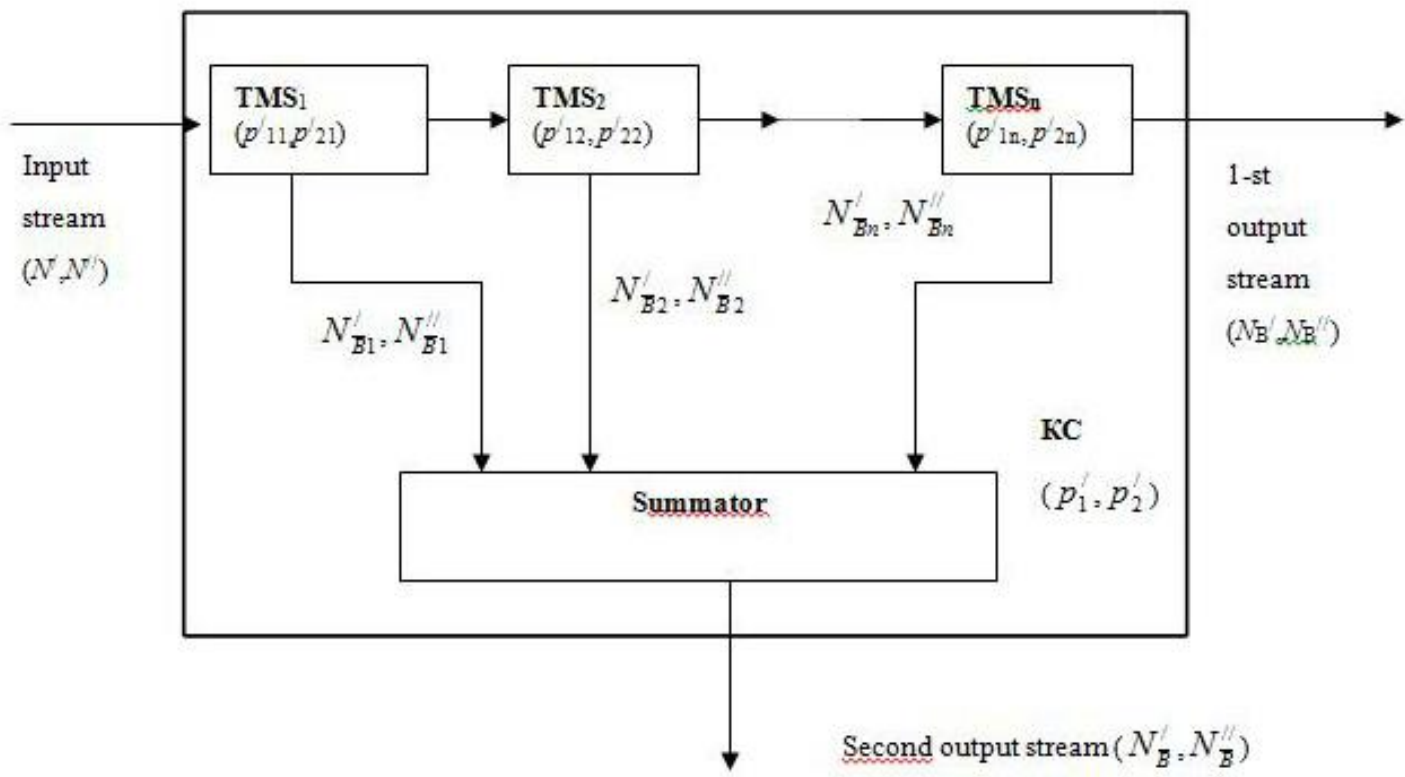

Fig. 3: The structure of the sequential TMS

TMS - monitoring system (composite),

$\boldsymbol{T M} \boldsymbol{S}_{i}, p_{1 i}^{\prime}, p_{2 i}^{\prime}, i=1,2, \ldots, n$ - typical MS and its parameters

2. For an exhaustive description of the TMS functioning, it is enough to dispose of two probability rates: the a priori conditional risk of the producer and the a priori conditional risk of the customer.

3. Each of the informative parameters of the TMS output streams chosen as its variable, depends only on one - the similar informative parameter of the input MS flow and it is related to it by the proportionality. A priori conditional risks or their complements up to unity act as the proportionality coefficients.

We use the standard symbolism during the mathematical expansion of these dispositions [10 - 12].

We designate by way of $N, N_{B}$ and $N_{\bar{B}}$ accordingly, the volumes of the input, the first output, and the second output stream. 
We label the same symbols with a stroke on top to quantities of fit, and with two strokes to the number of objects that are not fit in the proper flows. The a priori conditional risks of the producer and the customer will be designated by the symbols $p_{1}^{\prime}$ and $p_{2}^{\prime}$, and their augmenters up to unity by the symbols $\bar{p}_{1}^{\prime}$ and $\bar{p}_{2}^{\prime}$

$$
\bar{p}_{1}^{\prime}=1-p_{1}^{\prime} ; \quad \bar{p}_{2}^{\prime}=1-p_{2}^{\prime} \text {. }
$$

Using these symbols, the dependencies indicated in position 3 appear in the following form

$$
\begin{aligned}
& N_{B}^{\prime}=\bar{p}_{1}^{\prime} N^{\prime} ; N_{B}^{\prime /}=p_{2}^{\prime} N^{\prime \prime} ; \\
& N_{\bar{B}}^{\prime}=p_{1}^{\prime} N^{\prime} ; N_{\bar{B}}^{\prime \prime}=\bar{p}_{2}^{\prime} N^{\prime \prime} .
\end{aligned}
$$

It follows from the above, that the indicators $\bar{p}_{1}^{\prime}$ and $p_{2}^{\prime}$ act as the coefficients for the transfer of the quantities of fit and unfit objects, respectively, at the first output of MS, $\bar{p}_{2}^{\prime}$ and $p_{1}^{\prime}$ - at its second output.

We also note that only two of these four indicators (in any combination with different lower indices) are independent. Here we will be mainly interested in the indicators $p_{1}^{\prime}$ and $p_{2}^{\prime}$. The other two indicators are used only to simplify the computations.

Since the sum of the quantities of fit and unfit objects of the flow gives its volume, then

$$
N=N^{\prime}+N^{\prime \prime} ; \quad N_{B}=N_{B}^{\prime}+N_{B}^{\prime \prime} ; \quad N_{\bar{B}}=N_{\bar{B}}^{\prime}+N \frac{/}{\bar{B}} .
$$

For a sufficiently large volume of the input flow $\mathrm{N}$ (in the limit tending to infinity) the next propositions are valid:

$$
N^{\prime}=p N ; \quad N^{\prime \prime}=\bar{p} N=(1-p) N,
$$

where, $p$ и $\bar{p}-$ a priori probabilities, respectively, of the fitness and unfitness of an arbitrarily taken object of the flow (test lot); $N, N^{\prime}, N^{\prime \prime}$ - characteristic parameters of input and output streams of TMS

\subsection{Characteristics of the Sequential MS}

Let turn our attention to the dependence (2). It is valid for any MS, including for TMS. Let us single out the first of these dependencies

$N_{B}^{\prime}=N^{\prime} \cdot \bar{p}_{1}^{\prime}$

Consistently applying it with respect to each $\mathbf{T} \mathbf{M S} \mathbf{S}_{i}$, (see Fig. 3), we will obtain:

$$
\begin{aligned}
& N_{B 1}^{\prime}=N^{\prime} \bar{p}_{11}^{\prime}, \\
& N_{B 2}^{\prime}=N_{B 1}^{\prime} \bar{p}_{12}^{\prime}=N^{\prime} \bar{p}_{11}^{\prime} \bar{p}_{12}^{\prime}, \\
& N_{B 3}^{\prime}=N_{B 2}^{\prime} \bar{p}_{13}^{\prime}=N^{\prime} \bar{p}_{11}^{\prime} \bar{p}_{12}^{\prime} \bar{p}_{13}^{\prime}, \\
& N_{B}^{\prime}=N_{B n}^{\prime}=N_{B, n-1}^{\prime} \bar{p}_{1 n}^{\prime}=N^{\prime} \bar{p}_{11}^{\prime} \bar{p}_{12}^{\prime} \cdots \bar{p}_{1, n-1}^{\prime} \bar{p}_{1 n}^{\prime} .
\end{aligned}
$$

On the other hand, the dependence (5.6) is valid for a sequential MS as a whole, where $\bar{p}_{1}^{\prime}$ - one of its indicators (the addition of an a priori conditional risk to unity). Comparing (6) with the last row (7), we have

$$
\bar{p}_{1}^{\prime}=\prod_{i=1}^{n} \bar{p}_{1 i}^{\prime},
$$

that for transition to the a priori-conditional risks of the producer (see (1)) gives

$$
p_{1}^{\prime}=1-\Pi\left(1-p_{1 i}^{\prime}\right)
$$

To find the second index of the sequential MS, we write out the second dependence (2)

$$
N_{B}^{/ /}=N^{/ /} p_{2}^{\prime}
$$

Similarly to the previous case, applying it consistently to each model TMS, we finally find

$$
N_{B}^{\prime /}=N_{B n}^{\prime /}=N^{\prime /} p_{21}^{\prime} p_{22}^{\prime} p_{23}^{\prime} \cdots p_{2 n}^{\prime}
$$

from which (compare with the previous notation) the desired result follows

$$
p_{2}^{\prime}=\prod_{i=1}^{n} p_{2 i}^{\prime}
$$

Thus, with a series-parallel connection of two or more typical monitoring systems (which, in particular, occurs in a sequential TMS), their a priori-conditional customer risks and additions to the unit of a priori-conditional risks of the producer are multiplied and making corresponding indicators (a priori conditional risk of the customer and the addition of the producer's a priori conditional risk) of the connection as a whole.

Relations (8) and (9) are precise analytical representations of the a priori conditional risks of the producer and the customer, which exhaustively describe the functioning of the serial TMS.

They are simple, physical, obvious, convenient to use in the engineering practice.

Knowing them, it is easy to calculate all parameters of the output flows of the compressor station (their volumes, the degree of contamination by objects of the opposite quality, etc.), and also to assess the effectiveness of the sequential control as a whole.

\section{Practical Use}

The result of sequential control was practically used in the study of broccoli cabbage during its storage. Antimicrobials were used.

Fresh vegetables even at optimal temperatures and humidity have a limited shelf life.

The reasons for this are large natural weight and quality losses due to diseases and physiological processes.

Besides, the fresh appearance, consistence and content of useful components deteriorate. Up to $25 \%$ of fresh products are lost due to diseases even under optimal storage conditions.

To overcome these drawbacks, the vegetables are treated with antiseptic preparations before storage.

This treatment is aimed at preserving the quality and weight of vegetables. A review of literary sources has shown that scientific literature in this field is insufficient. Actual is the development of new storage technologies with the use of antiseptic drugs. The aim of the study was to study the effect of antimicrobial agents on the quality of broccoli to determine the shelf life of the broth, depending on the preparation $[15,17,18]$.

To achieve this goal the following tasks were accomplished: 
- determine the natural weight losses during storage;

- to study the defeat of cabbage by various diseases;

-to investigate the change in the components of the chemical composition during storage;

-to compare the quality of cabbage when storing, depending on the treatment with different preparations.

During the study, a sequential control of different in nature indicators. To find the optimal economic variant for the manufacturer, different varieties of cabbage and the most effective preparations for storage. This in turn affected the increase of the competitiveness of the option chosen by the manufacturer and the reduction of the economic losses. The output of standard products after storage by traditional technologies is $76.8-88.2 \%[17,18]$.

Among the natural antioxidants of phenolic nature for the storage of high antioxidant activity is in the possession of rutin. The role of the main synergist in routine belongs to ascorbic acid (AK). The study of the effect of drugs on the storage of cabbage used Baikal UM-1. Cabbage was stored in a refrigerator at a temperature about 0 . Conducted sequential control and further analysis of variance showed that treatment with drugs (factor A) by $19 \%$ affects the yield of commercial products. The degree of influence of the characteristics of the hybrid (factor B) was 5.7\%. The combined effect of these 2 factors is $25.7 \%$. Other factors affected $49.7 \%$. The natural losses of cabbage mice were significantly smaller $(\mathrm{NIR}=0.2 \%)$ compared to controls $[17,18]$. The data obtained in the sequential control are presented in Table 2.

Table 2: Preservation of broccoli cabbage depending on the treatment with antimicrobial agents

\begin{tabular}{|c|c|c|c|c|c|c|}
\hline \multicolumn{2}{|c|}{ Options } & \multirow{3}{*}{$\begin{array}{l}\text { shelf } \\
\text { life }\end{array}$} & \multicolumn{3}{|c|}{ loss of production } & \multirow{3}{*}{$\begin{array}{l}\text { output } \\
\text { of sta- } \\
\text { ndard } \\
\text { prod- } \\
\text { ucts }\end{array}$} \\
\hline & & & \multicolumn{2}{|c|}{ natural } & \multirow{2}{*}{$\begin{array}{l}\text { from } \\
\text { diseases } \\
\text { and phy- } \\
\text { siological } \\
\text { disorders }\end{array}$} & \\
\hline & & & total & per day & & \\
\hline \multirow{6}{*}{$\begin{array}{l}\text { Ay } \\
\text { ro } \\
\text { nm } \\
\text { en } \\
\text { F1 }\end{array}$} & PP & 30 & 4.8 & 0.16 & 16.6 & 78.6 \\
\hline & $\begin{array}{l}\text { Baycal } \\
\text { EM-1 }\end{array}$ & $\begin{array}{l}35- \\
50\end{array}$ & $3.9-4.5$ & $\begin{array}{l}0.11- \\
0.13\end{array}$ & 17.3 & 82.6 \\
\hline & LA & $\begin{array}{l}30- \\
40\end{array}$ & $3.4-5.0$ & $\begin{array}{l}0.1- \\
0.13\end{array}$ & 15.6 & 84.0 \\
\hline & SA & $\begin{array}{l}30- \\
35\end{array}$ & $2.2-2.9$ & $\begin{array}{l}0.07- \\
0.09\end{array}$ & 18.4 & 86.9 \\
\hline & BA & $\begin{array}{l}30- \\
40\end{array}$ & $2.4-3.7$ & $\begin{array}{l}0.08- \\
0.09\end{array}$ & 16.3 & 83.8 \\
\hline & $\mathrm{C}+\mathrm{P}$ & $\begin{array}{l}35- \\
45\end{array}$ & $3.3-4.5$ & $\begin{array}{l}0.09- \\
0.1\end{array}$ & 14.4 & 86.2 \\
\hline \multirow{6}{*}{$\begin{array}{l}\mathrm{Ar} \\
\mathrm{ac} \\
\mathrm{ci} \\
\mathrm{F} 1\end{array}$} & $\mathrm{PP}$ & $\begin{array}{l}20- \\
25\end{array}$ & $3.8-5.6$ & $\begin{array}{l}0.19- \\
0.23\end{array}$ & 18.1 & 78.1 \\
\hline & $\begin{array}{l}\text { Baycal } \\
\text { EM-1 }\end{array}$ & $\begin{array}{l}25- \\
40\end{array}$ & $3.7-6.1$ & 0.15 & 16.7 & 80.8 \\
\hline & LA & $\begin{array}{l}25- \\
35\end{array}$ & $3.4-3.9$ & $\begin{array}{l}0.14- \\
0.15\end{array}$ & 16.4 & 83.3 \\
\hline & SA & $\begin{array}{l}25- \\
25\end{array}$ & $2.1-3.3$ & $\begin{array}{l}0.11- \\
0.13\end{array}$ & 17.6 & 86.8 \\
\hline & $\mathrm{BA}$ & $\begin{array}{l}20- \\
25\end{array}$ & $2.2-3.5$ & $\begin{array}{l}0.11- \\
0.14\end{array}$ & 15.1 & 87.6 \\
\hline & $\mathrm{C}+\mathrm{P}$ & $\begin{array}{l}30- \\
45\end{array}$ & $3.6-5.7$ & $\begin{array}{l}0.12- \\
0.13\end{array}$ & 17.0 & 83.6 \\
\hline \multirow{6}{*}{$\begin{array}{l}\text { Bo } \\
\text { mo } \\
\text { nd } \\
\text { F1 }\end{array}$} & $\mathrm{PP}$ & 30 & 4.6 & 0.15 & 14.7 & 80.7 \\
\hline & $\begin{array}{l}\text { Baycal } \\
\text { EM-1 }\end{array}$ & $\begin{array}{l}35- \\
45\end{array}$ & $2.9-4.4$ & $\begin{array}{l}0.08- \\
0.01\end{array}$ & 15.3 & 82.7 \\
\hline & LA & $\begin{array}{l}30- \\
35 \\
\end{array}$ & $2.6-3.3$ & $\begin{array}{l}0.09- \\
0.1 \\
\end{array}$ & 15.4 & 85.3 \\
\hline & SA & $\begin{array}{l}25- \\
45\end{array}$ & $1.3-3.1$ & $\begin{array}{l}0.05- \\
0.07\end{array}$ & 18.4 & 88.2 \\
\hline & BA & $\begin{array}{l}30- \\
40\end{array}$ & $1.9-3.1$ & $\begin{array}{l}0.06- \\
0.08\end{array}$ & 17.3 & 85.6 \\
\hline & $\mathrm{C}+\mathrm{P}$ & $\begin{array}{l}45- \\
50\end{array}$ & $3.2-4.3$ & $\begin{array}{l}0.07- \\
0.09\end{array}$ & 14.1 & 84.8 \\
\hline \multicolumn{2}{|c|}{$\begin{array}{l}\text { HIP0,5A } \\
\text { HIP0,5B } \\
\text { HIP0,5AB }\end{array}$} & 2 & $\begin{array}{l}0.2-0.3 \\
0.1-0.2 \\
0.3-0.5\end{array}$ & $\begin{array}{l}0.01 \\
0.01 \\
0.02\end{array}$ & $\begin{array}{l}2.2-3-5 \\
1.6-2.5 \\
3.9-6.0\end{array}$ & $\begin{array}{l}2.3-3.6 \\
1.6-2.5 \\
3.9-6.2\end{array}$ \\
\hline
\end{tabular}

Note: PP-storage of raw cabbage; LA-citric acid; CA-sorbic acid; BA-benzoic acid; $C+P$-ascorutin.
Studies have shown that ascorutin better than other drugs inhibited the intensity of development of pathogenic bacteria. The first signs of illness appeared 10-15 days later. Ascorutin provided for longterm storage and less weight loss of $0.8-2.2 \%$ and from physiological disturbances. A greater yield of marketable output was achieved by $4.7-7.6 \%[17,18]$.

Dispersion analysis of data obtained by means of sequential monitoring showed the following. The affected cabbage heads were observed on the 30th day $-9.8 \%$ of storage when treated with citric acid. The lesion was observed on day 20 when treated with sorbic and benzoic acid as in the control variant.

But the losses were fixed respectively 1.1 and 1.9 times smaller.

The results of a study of broccoli cabbage using sequential control showed the following $[17,18]$ :

1. Preparations of antimicrobial action contributed to the continuation of the shelf life of cabbage for 5-20 days, depending on the hybrid. Application of Baikal EM-1 and ascorutin promoted the prolongation of storage up to 40-50 and 45-50 days. Ascorutin provided, with long-term storage, a smaller mass loss from illnesses and physiological disturbances.

At the same time, there was a greater yield of commodity products by $7.6 \%$ on average.

2. Processing broccoli with antiseptics provided a dry matter content of 1.2-2, 2 times greater than in the control. It also helped reduce the loss of dry matter and vitamin C. At the end of storage, the content of total sugar and disaccharides exceeded its content in the control, respectively, by 1.2 and 1.5 2.0 times. The content of monosaccharides was maintained at the initial level.

The loss of mass due to evaporation of water was 1.3-1.8 times more.

3. More actively inhibited the development of pathogenic bacteria on broccoli cabbage ascorutin, citric, sorbic and benzoic acid.

\section{Conclusions.}

One of the practical ways to increase the effectiveness of control is to construct it in a repeating system, when an object that is recognized as fit is subject to repeated check. In this section, such control is called sequential control.

Despite its common industrial introduction, theoretical developments are kept abreast of the practice needs. In particular, its defining characteristics have not been established, methods for their calculation have not been proposed.

Studies proposed in this article, according to the authors' opinion, eliminate this gap. The decisions are based on the general laws of numerical control which were established earlier in the article $[10$, 12-16]:

- any monitoring system (TMS) is exhaustively described by the a priori conditional risks of the producer and the customer;

- each output variable of the TMS is related to the input variables of the same name by the proportionality.

When general levels attaining of the manufacturer and the customer risks stipulated in trade agreements this statistical approach makes it possible to evaluate the contribution to the overall qualitative result of individual control subsystems (chemical, physical, biological ...).

The "Control tolerance corridor" for individual subsystemscan be used. Under the condition of a critical approximation to the tolerance limit of one of the subsystems, one can combine the a prioriconventional risk of other subsystems.

When a critical approximation to the tolerance limit of control of the a priori conventional risk of an individual subsystem, its contribution to the overall risk can be compensated by the variation of the quantitative changes in the risks of other subsystems.

This general combination of risks of different subsystems will allow to come out in accordance with the obtained result of the research (8) and (9) on the implementation of the general standard 
of the manufacturer and the customer given risks in the agreements.

We are not talking about the violation $0,05-0,07$ of certain standards, but only about new opportunities for general compensation by individual subsystems.

This approach allows a qualitative assessment string of the marketable agricultural produce from its production - processing transportation to marketing.

This general statistical approach will improve the management of product quality and increase its competitiveness.

Precise analytical relations are deduced that relate the exhaustive characteristics of the coprocessor to the corresponding characteristics of its rectangular structural elements.

They are reduced to an extremely simple rule: in order to find the a priori conditional risk of the customer and the addition to the unit of a priori conditional risk of the producer of the sequential TMS as a whole.

It is necessary to multiply the corresponding indices (the a priori conditional risks of the customer and the a priori conditional producer's risks) of all its rectangular elements (TMS).

The consistency of this result is shown. With statistical control, the acceptable level of quality varies from $0.5 \%$ to $1 \%$.

Selective control provides a $10 \%$ risk to the consumer.

In standards for statistical control, the risks of the supplier $\alpha$ and consumer $\beta$ do not exceed $0.01 ; 0.05$ and 0.1 . Sequential control, multi-stage and 2-step control ensure greater precision of the decisions taken with the same sample size [1, 2, 13, 14].

The two-stage control reduces the risks of the supplier to $\alpha=0,025 \%$. One-step control reduces the supplier's risks for $\beta=0,046 \%$. But they are difficult to organize and require additional computing operations.

The obtained result is invariant with respect to different types of numerical control (measuring - not measuring, one-parameter multi-parametric, direct-indirect, etc.).

The analytical dependencies arising from it are convenient in engineering calculations and can serve as reference relations in evaluating the effectiveness of sequential and other complex structures of control.

\section{References}

[1] DSTU ISO 9004 - 2001. System management quality. Decisions on improvement of activities (2001), Derzhstandart of Ukraine. - p.70.

[2] DSTU 2865 - 94. Control non-destructive. Terms and definitions. (1995). Derzhstandart of Ukraine. - p. 52.

[3] Bolychevthev A.D., Bolychevtheva L.A. \& Shlykov V.A. Sequential control. Control system and its characteristics (2004). M: Journal Metrology. (In Russ.), 9, 3-16.

[4] Bolychevthev A.D., Multistage measuring control (1990). M: Jour nal Measuring Technology (In Russ.), 8, 15-17.

[5] Bolychevthev A.D., Bolychevtheva LA, Bistrythskaya LB \& Lyubymova N.A. Sequential control and his mathematic model (2011). (In Ukr.). Journal Bulletin Kherson National Technical University, 3 (42), 99-103.

[6] Dmitrithenko M.I., Expertise of quality and detection of falsification of food products (2003), (In Belorus., In Ukr.), Minsk, Kiev, P.137-152.

[7] Volodarsky E.T., Kuharchuk B.O., Podgarenko G.B. \& Serduk G.B., Metrological support measurements and control (2001). (In Ukr.), - Vinnicya: Veles. - p. 219.

[8] Malaytchuc V.P., Information-measuring technology контролю control non-destructive (2001). (In Ukr. ) Dnipro: RVV DDU. p. 240 .

[9] Ilyenkova S.D., Management of quality (1998). (In Russ.) M.: Bank and stock exchange. p. 267.

[10] Bolychevthev A.D., Numerical measurement control increase quality (1990), M: Journal Measuring Technology, (In Russ.) 5, 13-15.

[11] Fedushin A.I., (2004), One way of improve authenticity numerical measurement control, Kiev: Ukraine Metrology Journal 1, 14-17.

[12] Bolychevthev A.D. (2000), Control as a guarantor of product quality and requirements for the accuracy of the measuring equipment used M: Journal Metrology. (In Russ.), 11, 20-32.
[13] Grin I.V. Quality control (2008). Rrasnodar College of Electronic Engeeniring (In Russ.). P.56.

[14] Byktimirov R.L. Quality control, personal and logistic engeeniring. (2005). S.-P. (In. Russ. ). P. 237.

[15] Bogdanovych E.N. Statistichesky priyomochny control (2012). Vo ronezh: FGBOU VPO. Voronezh State Technical University. Study guide. $-120 \mathrm{p}$.

[16] Dzirkal E.V. N.O. Demidovich`s sequential control method. Dependability. 2014;(3):137-150. (In Russ.) DOI:10.21683/1729-2646-2014-0-3-137-150.

[17] Puzik L.M. \& Bondarenko V.A. (2014), Aapplication of antimicrobial agents for storing broccoli, Journal Vegetable growing and melons. (In Ukr), Kharkov, 60, 226-231.

[18] Puzik L.M. \& Bondarenko V. (2013), A disease of cabbage broccoli during storage, depending on the treatment with Baikal EM-1 Journal plant growing, selection and seed-growing and vegetable growing (In Ukr.), 9, 231 - 234. 